\title{
0 mercado de trabalho para o profissional da hotelaria na cidade de Limoeiro do Norte - CE
}

The job market for the hospitality professional in Limoeiro do Norte city - CE El mercado de trabajo para el profesional de la industria de la hospitalidad en la ciudad de Limoeiro do Norte - CE

http://dx.doi.org/10.18472/cvt.18n3.2018.1342

Edvanda Maria Melo Maia 〈edvandamel@gmail.com >

Instituto Federal de Educação, Ciência e Tecnologia do Ceará (IFCE), Limoeiro do Norte, CE, Brasil.

CRONOLOGIA DO PROCESSO EDITORIAL

Recebimento do artigo: 13-out-2016

Aceite: 02 -jul-2018

FORMATO PARA CITAÇÃO DESTE ARTIGO

MAIA, E. M. M. O mercado de trabalho para o profissional da hotelaria na cidade de Limoeiro do Norte - Ceará. Caderno Virtual de Turismo. Rio de Janeiro, v. 18, n. 3, p. 79-92, dez. 2018.

REALIZAÇÃO

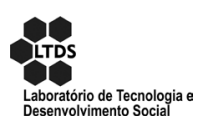

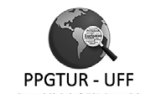

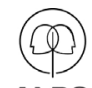

IABS
APOIO INSTITUCIONAL

COPPE

UFR]

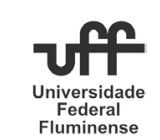

EDIÇÃO

PATROCÍNIO

EDITOR日

\section{Q6) FAPER}




\section{RESUMO}

O presente artigo pretende conhecer o mercado de trabalho para o profissional da hotelaria na cidade de Limoeiro do Norte - Ceará. Este tem como objetivo principal analisar a empregabilidade do aluno egresso do curso de Tecnologia em Hotelaria oferecido pelo Polo de Apoio Presencial da Universidade Aberta do Brasil na referida cidade. Entre os objetivos específicos, inclui-se o de investigar o perfil do profissional de hotelaria requerido pelos meios de hospedagem da cidade e o de verificar as possibilidades de trabalho para os alunos egressos do curso no setor hoteleiro do município. Ao final do estudo, pôde-se concluir que os alunos egressos do curso não têm encontrado colocação nos empreendimentos hoteleiros da cidade e da região como um todo e que esses estabelecimentos não exigem uma formação técnica ou acadêmica na área como requisito para contratação de sua mão de obra. Essa mesma realidade foi verificada em outros estudos sobre o tema. A maioria destes constatou que isso ocorre devido à falta de sintonia entre as instituições de ensino superior e o mercado de trabalho, que têm expectativas divergentes no tocante à formação que deve ser ofertada ao profissional da área.

Palavras chave: Mercado de trabalho. Perfil profissional. Qualificação profissional. Hotelaria.

\section{ABSTRACT}

This work intends to explore the job market for the hospitality professional in Limoeiro do Norte city - in Ceará. Its main goal is to analyze the employability of the graduate students from the Tecnologia em Hotelaria course offered by Polo de Apoio Presencial da Universidade Aberta do Brasil in the previous mentioned city. As for the specific goals, there is the investigation of the hospitality professional profile required by the hosting sites of the cities. In addition, to verify the job possibilities for the course graduate students in the hotel sector in the city. By the end of this study, it was possible to conclude that the course graduate students have not found jobs in the hotel sites in the city and the region as a whole; and these establishments do not demand a technical or academic graduation in the area as a requirement for hiring their workmanship. This same reality was verified in other studies concerning the theme. Most of them has shown that this happens due to a lack of tune between the higher education institutions and the job market, which have divergent expectations concerning the qualification that should be provided to the professional in this area.

Keywords: Job market. Professional profile. Professional qualification. Hospitality.

\section{RESUMEN}

El presente artículo pretende conocer el mercado de trabajo para el profesional de la hostelería en la ciudad de Limoeiro do Norte - Ceará. Este tiene como objetivo principal analizar la empleabilidad del alumno egresado del curso de Tecnología en Hotelería ofrecido por el Polo de Apoyo Presencial de la Universidad Abierta de Brasil en la referida ciudad. Entre los objetivos específicos, se incluye el de investigar el perfil del profesional de hotelería requerido por los medios de hospedaje de la ciudad y el de verificar las posibilidades de trabajo para los alumnos egresados del curso en el sector hotelero del municipio. Al final del estudio, se pudo concluir que los alumnos egresados del curso no han encontrado colocación en los emprendimientos hoteleros de la ciudad y de la región como un todo y que esos establecimientos no exigen una formación técnica o académica en el área como requisito para contratación de su mano de obra. Esta misma realidad se verificó en otros estudios sobre el tema. La mayoría de éstos constató que esto ocurre debido a la falta de sintonía entre las instituciones de enseñanza superior y el mercado de trabajo, que tienen expectativas divergentes en cuanto a la formación que debe ser ofrecida al profesional del área.

Palavras clave: Mercado de trabajo. Perfil profesional. Cualificación profesional. Hospitalidad. 


\section{INTRODUÇÃO}

De acordo com o World Travel \& Tourism Council (2018), o turismo foi responsável pela injeção de R\$ 520,5 bilhões no Brasil em 2017, o equivalente a 7,9\% do Produto Interno Bruto (PIB) brasileiro no ano. O valor representa o crescimento de 7\% em relação ao ano anterior. O setor gerou 6,59 milhões de postos de trabalho no mesmo período, sendo 2,33 milhões de empregos diretos.

Em estudo realizado pela Secretaria de Turismo do Estado do Ceará (2017), o impacto do turismo no PIB do estado saltou, no período de 2006 a 2016, de 9,4\% para 11,7\%. A renda gerada pelo setor também evoluiu, passando de 4,5 bilhões de reais para 9,6 bilhões de reais, o que representa um aumento de $120,2 \%$. No mesmo período, a demanda hoteleira teve um crescimento anual de 5,2\%.

Conhecido como um povo acolhedor, o cearense se sobressai no quesito hospitalidade, cativando os seus visitantes, de modo que estes se sentem atraídos a retornar sempre que possível. No entanto, o conceito de hospitalidade é mais complexo do que apenas "o jeito de ser de um povo". É necessário que haja, ao mesmo tempo, investimentos na qualificação dos profissionais da área, uma vez que esse mercado tem se mostrado cada vez mais competitivo, exigindo, acima de tudo, a excelência dos serviços ofertados.

Nesse sentido, os prestadores de serviços turísticos, como agências de viagem, organizadoras de eventos, meios de hospedagens, entre outros, precisam se adaptar rapidamente às demandas dos novos consumidores. É sabido que esse público, como relatado anteriormente, vem exigindo a oferta de produtos e serviços de boa qualidade.

É nesse novo contexto que os meios de hospedagens passam a ocupar uma posição de destaque dentro da cadeia produtiva do turismo, uma vez que são os responsáveis por acolher o turista durante a sua estada em um habitat diferente do seu. Esses empreendimentos têm uma importante missão: fazer com que seus hóspedes se sintam em casa, mesmo não estando nela.

No intuito de municiar o mercado cearense com profissionais qualificados, o Instituto Federal de Educação, Ciência e Tecnologia do Ceará (IFCE), em parceria com a Universidade Aberta do Brasil (UAB), instituiu o Curso de Tecnologia em Hotelaria na modalidade a distância. E no ano de 2007 deu-se início à primeira turma do Curso de Tecnologia em Hotelaria oferecida pelo polo de apoio presencial da UAB em Limoeiro do Norte.

Limoeiro do Norte, município situado a leste do estado do Ceará, na macrorregião Vale do Jaguaribe, localiza-se a cerca de 162,0 quilômetros de Fortaleza e foi incluído pelo Ministério do Turismo (MTur) no Mapa do Turismo Brasileiro 2013, documento que apresenta as regiões e municípios consagrados como destinos turísticos no País, bem como os municípios com potencial para o desenvolvimento da atividade turística. Outras três cidades da região também foram incluídas nesse mapa: Jaguaribara, Jaguaribe e Morada Nova.

Diante desse contexto, o presente estudo visa conhecer o mercado de trabalho para o profissional da hotelaria em Limoeiro do Norte, tendo como objetivo principal analisar a empregabilidade do aluno egresso do curso de Tecnologia em Hotelaria existente na cidade. Entre os objetivos específicos, estão: investigar o perfil do profissional de hotelaria requerido pelos meios de hospedagem da cidade e verificar as possibilidades de trabalho para os alunos egressos do curso no setor hoteleiro do município. 
Para alcançar esses objetivos, foi realizada uma pesquisa qualiquantitativa de caráter exploratório, executada por meio da realização de entrevistas com os proprietários de quatro meios de hospedagens locais, além da aplicação de 18 questionários semiestruturados com os alunos egressos do curso de Tecnologia em Hotelaria do polo Limoeiro do Norte.

A necessidade da realização do estudo surgiu a partir da inquietação de muitos concludentes do referido curso, ainda no ano de 2010 (ano em que a primeira turma colou grau), em relação à possibilidade ou não de ingressarem no mercado de trabalho local por meio da qualificação conferida pela graduação. Desde então, os alunos do curso se questionam se os hotéis e similares da cidade estariam dispostos a absorver a mão de obra qualificada disponível.

Destarte, a execução desta pesquisa se torna relevante na medida em que oferece aos alunos egressos e aos que pretendem ingressar no curso um panorama atualizado da realidade local desse setor produtivo. Com isso, esse público poderá se adequar às exigências dos meios de hospedagens e do mercado de trabalho, tendo a oportunidade de, assim, aumentar sua empregabilidade.

\section{QUALIFICAÇÃO: A CHAVE PARA O SUCESSO?}

É consenso entre os autores que se dedicam ao estudo do Turismo que a qualificação da mão de obra empregada em um empreendimento do setor é um fator decisivo para a sobrevivência deste em um mercado tão competitivo e globalizado.

Para Robledo, Arán e Pérez-Aranda (2015), o empregado é a chave para a percepção da qualidade do serviço por parte dos clientes, devendo seu conhecimento ser considerado um recurso estratégico para o empreendimento. Assim, investir na qualificação desse profissional, principalmente daqueles que entram diretamente em contato com o hóspede, é imprescindível para garantir a rentabilidade e a vantagem competitiva da empresa hoteleira, uma vez que a excelência do serviço prestado está diretamente relacionada com a qualificação das pessoas que o executam.

Beni (2001) acrescenta que a qualidade também se alicerça no comportamento do homem ao qual é confiada a responsabilidade pelo serviço. Para o autor, é no homem e no local onde o serviço é prestado que está o perigo de a expectativa da demanda não ser satisfeita.

Para Caon (2008 apud CONCEIÇÃO; FRAGA, 2016), a falta ou insuficiência da qualificação dos profissionais que atuam no contato direto com o cliente impacta no nível de satisfação deste em relação ao serviço prestado.

De acordo com Fu, Yang e Chu (2014 apud SANTOS; SILVA, 2015), a qualificação assume papel decisivo no ciclo de vida, na produtividade e competitividade de empresas hoteleiras, visto que um capital humano melhor capacitado é capaz de elevar seus resultados operacionais, administrativos e financeiros.

Broncano e Andrés (2009) salientam que o trabalhador não deve ser visto como um mero executor de regras e procedimentos prescritos pela administração e sim como interlocutor direto entre a empresa e o cliente e como o único capaz de, ao identificar suas necessidades, oferecer-lhe um serviço personalizado e de excelente qualidade. 
Porém, não basta investir somente em programas de capacitação técnica para se atingir a excelência do serviço, é preciso atentar também para a satisfação do funcionário em seu ambiente de trabalho.

Robledo, Arán e Pérez-Aranda (2015) destacam que, para se conseguir a fidelização do cliente, as empresas devem manter satisfeitos primeiramente seus colaboradores, pois só assim eles estarão motivados a oferecer o serviço com a qualidade esperada.

Percebe-se, assim, que a qualificação do capital humano é condição sine qua non para manter a rentabilidade e a competitividade das empresas que prestam serviços, principalmente serviços turísticos/ hoteleiros. O profissional qualificado pode ser considerado responsável, em grande parte, pelo sucesso ou fracasso de tais empresas.

Destarte, algumas indagações se mostram essenciais: quais características definem o profissional qualificado? Qual é o perfil do profissional procurado pelas empresas que prestam serviços turísticos, especialmente pela hotelaria? Sendo mais específico ainda, qual o perfil do profissional requerido pelos meios de hospedagem da cidade de Limoeiro do Norte?

\section{PERFIL DO PROFISSIONAL DE HOTELARIA}

Não existe um perfil predefinido de um profissional qualificado para atuar na hotelaria. Na verdade, esse perfil depende, em grande parte, da realidade local, do perfil do cliente atendido pelo empreendimento e de outras características que tornam cada meio de hospedagem único.

A existência dessas peculiaridades torna praticamente impossível traçar um perfil único e homogêneo para esse profissional, o que pode dificultar no momento da escolha de um curso de capacitação ou de ingresso no mercado de trabalho.

Ademais, existem outros atores que precisam ser considerados no momento da busca pela definição de um perfil para o profissional que atuará na área: as instituições de ensino, que são responsáveis pela oferta de qualificação técnica, e o próprio profissional que deve ter seus anseios levados em conta.

Todavia, esses agentes nem sempre estão em consenso, é o que mostra estudos como o de Pimentel et al. (2018). Segundo os autores, as instituições de ensino possuem uma visão voltada para aspectos teóricos e pouco ligados ao mercado de trabalho, o que leva os empresários a apontarem a pouca ou nenhuma relação entre a formação e a atividade de seus estabelecimentos comerciais, acreditando, muitos deles, que essa formação é desnecessária.

Essa é a mesma conclusão a que chega o MTur (2015). Para o órgão, há uma forte inadequação dos cursos superiores de Turismo em face das reais demandas do setor. Ele acrescenta que uma formação excessivamente generalista do turismólogo, com deficiências em gestão e pouco espírito prático, é o motivo para a baixa absorção desse profissional no mercado de trabalho.

A entidade ainda aponta para a necessidade da realização de diagnósticos que proporcionem a identificação das reais necessidades mercadológicas do setor e da reformatação dos cursos superiores de Turismo e Hotelaria no intuito de supri-las. 
Gaio e Fernandes (2006) acrescentam que os cursos superiores de Turismo vêm capacitando seus estudantes para assumirem cargos gerenciais, ao passo que, como demonstrado também por Pimentel et al. (2018), a maioria dos postos ocupados por profissionais de turismo relaciona-se com áreas operacionais, principalmente operações ligadas à venda.

Eurico, Silva e Vale (2012) chamam atenção para a necessidade de se instaurar uma relação mais estreita entre a comunidade empresarial, as instituições de ensino superior e os diplomados/profissionais de turismo no sentido de traçar estratégias para o atendimento das reais necessidades dos diferentes atores envolvidos.

Os autores acrescentam que a formação acadêmica, por si só, não é garantia de sucesso e progressão profissional do diplomado em Turismo. Ao estudar o sistema produtivo de Portugal, eles apontam sua incapacidade em assimilar os crescentes contingentes de diplomados, resultando em um crescimento do desemprego qualificado.

Hoerner e Sicart (2013 apud PIMENTEL et al. 2018), ao analisarem as necessidades do turismo da França e da Inglaterra, chegam à mesma conclusão. Eles afirmam que cerca de $80 \%$ dos egressos dos cursos superiores de Turismo não atuam no mercado de trabalho do setor. O que os leva a escolherem outras áreas do conhecimento para dar sequência à sua vida profissional.

Posto isso, percebe-se não ser tarefa fácil traçar um perfil que sirva para nortear o profissional formado, ou que planeje se formar, na área. Nem se pretende encerrar aqui a discussão sobre o tema, o qual demonstra ser demasiado complexo e necessita de uma coalizão de forças para a busca de uma direção que aponte para a solução dessa problemática.

No entanto, alguns autores dão sua contribuição para o debate ao listar algumas competências/ habilidades consideradas desejáveis para os que atuam na atividade turística/hoteleira.

De acordo com Fornari (2006 apud MOTA; SILVA, 2013), atributos e qualidades pessoais precisam estar aliados ao processo de qualificação e capacitação continuada.

A Associação Brasileira de Normas Técnicas (ABNT) formulou uma série de normas técnicas nas quais são descritos os conhecimentos, habilidades e atitudes/atributos (CHA) esperados de algumas profissões ligadas à atividade turística. Esse conjunto de normas foi editado para garantir a qualidade e segurança para o setor, servindo como importante referencial na estruturação do País para a Copa do Mundo FIFA de 2014.

Com base nessas normas técnicas, Mota e Silva (2013) identificaram o perfil profissional requerido pelos meios de hospedagens, agências de viagens e por órgãos públicos oficiais do turismo na cidade de Fortaleza, Ceará. Para as autoras,

um bom gerente na área deve apresentar competências para comunicar, planejar e gerir o setor onde atua, além daquelas específicas da profissão, destacando-se, principalmente: a multifuncionalidade, o domínio de línguas estrangeiras e o conhecimento teórico-prático da profissão (MOTA; SILVA, 2013, p. 25).

As autoras acrescentam ainda que na visão dos gestores de hotéis e afins e da Associação Brasileira da Indústria de Hotéis (ABIH) Ceará, as competências que merecem destaque são: domínio de línguas estrangeiras, conhecimento teórico-prático, habilidades interpessoais e habilidades técnicas específicas da área, em nível operacional e gerencial. 
Outros autores como Fornari (2006 apud MENDES; SANTOS, 2009) listam competências necessárias para que o profissional do setor hoteleiro participe do mercado de trabalho de maneira competitiva. Destacam-se as seguintes: ser criativo, ter capacidade de adaptar-se às mudanças; ser consciente de sua responsabilidade social e política; ser ético; ter iniciativa; saber trabalhar em equipe; possuir raciocínio lógico para analisar e diagnosticar situações; ser líder; saber tomar decisões com dinamismo; saber utilizar novas tecnologias e equipamentos; ter conhecimentos técnicos e ter domínio de idiomas.

Mendes e Santos (2009) relacionam os aspectos mais importantes na visão de gestores de meios de hospedagem e que mais são levados em consideração em três fases distintas: na pré-seleção, na contratação e na promoção de seus colaboradores. Na pré-seleção, assim como na contratação, os aspectos considerados os mais importantes são: experiência anterior na área e formação acadêmica na área, seguida de fluência em idiomas, formação em qualquer outra área e a indicação. Na promoção, os quesitos vistos como mais importantes foram habilidades técnicas, seguidas de habilidades interpessoais e habilidades pessoais.

Também levando em consideração a opinião de gestores de meios de hospedagem, Paiva, Santos e Lacerda (2014) apontam as seguintes competências como fundamentais: compreender a si mesmo e aos outros, comunicar-se eficazmente e contribuir para o desenvolvimento dos empregados; gerenciar projetos, planejar o trabalho e gerenciar de modo multidisciplinar; e trabalhar de modo produtivo, fomentar um ambiente de trabalho produtivo e gerenciar o tempo e o estresse (próprio e da equipe).

Já Melo e Gonçalves (2015), ao investigarem quais competências diretores de cursos de ensino superior de Turismo consideram elementares, assinalam o domínio dos conceitos de gestão aplicada; conhecimentos sobre contabilidade, gestão de recursos humanos, marketing e conceitos relacionados ao turismo; capacidades linguísticas e comunicacionais; conhecimentos sobre a realidade social, econômica e cultural do universo profissional que os aguardam; conhecimento sobre protocolos; saber conversar com as pessoas; domínio das tecnologias e habilidade com os recursos digitais; capacidade de comunicação oral e escrita em duas ou mais línguas estrangeiras; ser flexível e capaz de satisfazer os novos tipos de clientes com novas necessidades.

Como é possível perceber, não é somente a formação técnico-científica que é considerada na hora de se determinar quais competências são fundamentais para o profissional de turismo/hotelaria. Conforme Silva (2005 apud PEQUENO, 2012. p. 103), "o mundo globalizado exige profissionais com diversas habilidades e competências, tais como: multifuncionalidade, eficiência, criatividade, visão de futuro, entre outros".

Por se tratar de uma profissão que envolve o desempenho de atividades em diversos níveis, desde o operacional até o estratégico, bem como exige o contato, muitas vezes direto, com outras pessoas, demanda-se uma educação multidisciplinar, que proporcione ao profissional conhecimento das diversas áreas que compõem a empresa, além de habilidades interpessoais, sociais e vivências profissionais ao longo de sua formação.

Como dito anteriormente, devido à heterogeneidade característica do setor turístico/hoteleiro, não é possível se delimitar um perfil único, universal do profissional que nela atuará. Há que se levar em conta todas as características inerentes a essas atividades e principalmente considerar a realidade na qual o empreendimento está inserido.

É possível que determinado meio de hospedagem, falando agora especificamente do setor hoteleiro, exija boa parte dessas competências/habilidades elencadas acima na hora de selecionar seu colaborador, do mesmo modo que é compreensível que outro (de menor porte, por exemplo) exija poucas ou nenhuma 
delas, isso vai depender das idiossincrasias de cada empreendimento. Cabe ao seu gestor, montar o perfil do profissional que satisfaça as necessidades de seus clientes.

\section{METODOLOGIA}

A realização do presente estudo, que se deu entre os meses de março e junho de 2014, surgiu da necessidade de avaliar a situação de empregabilidade dos alunos concludentes do curso de Tecnologia em Hotelaria, ministrado pelo Instituto Federal de Educação, Ciência e Tecnologia do Ceará (IFCE), em parceria com a Universidade Aberta do Brasil (UAB). A partir de estudos iniciais, foi traçado o objetivo principal deste trabalho: analisar a empregabilidade do aluno egresso do referido curso na cidade de Limoeiro do Norte. Além disso, buscou-se traçar o perfil do profissional de hotelaria requerido pelos meios de hospedagem da cidade e verificar as possibilidades de trabalho para os alunos egressos do curso no setor hoteleiro do município.

Após a escolha do tema e definição dos objetivos, foi realizada uma ampla pesquisa bibliográfica relacionada ao tema, que permitiu fundamentar a estrutura teórica da pesquisa e adequar os objetivos e a metodologia de trabalho, envolvendo teoria e prática. Foram analisados, ainda, documentos e dados referentes ao desenvolvimento do setor de turismo, tanto em nível nacional como em nível local, no sentido de fomentar a relevância da pesquisa. Esta revisão bibliográfica baseou as considerações apresentadas ao longo da pesquisa, bem como auxiliou na elaboração dos questionários e na realização das entrevistas.

Em seguida, foi realizada visita aos quatro meios de hospedagem da cidade para a realização de entrevistas e aplicação de questionários. O universo da pesquisa foi dividido em dois grupos distintos. O primeiro é formado pelos responsáveis pelo setor de contratação dos meios de hospedagens existentes na cidade, que, na atualidade, resumem-se a apenas quatro estabelecimentos, e o segundo, por 18 alunos egressos do curso de Tecnologia em Hotelaria do polo Limoeiro do Norte.

Com os empresários do setor hoteleiro, foi realizado um questionário semiestruturado com 16 perguntas (abertas e fechadas) referentes ao estabelecimento e ao nível de qualificação de seus funcionários. As perguntas dirigidas a esses entrevistados tinham como finalidade identificar os tipos de estabelecimentos hoteleiros existentes na região e traçar um breve perfil dos funcionários, levando em conta alguns aspectos, tais como escolaridade e qualificação profissional. Buscou-se, ainda, saber quais exigências são levadas em consideração no momento de contratação. Nesse sentido, os interrogados foram questionados acerca do interesse na admissão de alunos egressos do curso de Tecnologia em Hotelaria.

Por sua vez, o questionário endereçado aos ex-alunos que concluíram satisfatoriamente o referido curso, além de traçar um perfil resumido desses profissionais, buscou enfatizar a questão da empregabilidade, procurando identificar as percepções dos alunos quanto às contribuições do curso para o seu currículo e as dificuldades encontradas na busca pela inserção e manutenção no mercado de trabalho, tanto nos estabelecimentos da região como de outros locais. 


\section{RESULTADOS}

\section{ALUNOS EGRESSOS DO CURSO DE TECNOLOGIA EM HOTELARIA}

De acordo com informações obtidas no polo de apoio presencial de Limoeiro do Norte, até o momento da finalização da pesquisa, 30 alunos haviam concluído o curso de Tecnologia em Hotelaria. No sentido de viabilizar a pesquisa com esse grupo, foi enviado um questionário através de correio eletrônico (e-mail) para todos os alunos que haviam logrado êxito nessa graduação.

Desse total, 18 enviaram o questionário respondido. Na tentativa de obter as respostas dos 12 alunos restantes, foi efetuado contato através de telefone e das redes sociais, porém, não se obteve nenhum retorno satisfatório. Assim, esse grupo foi formado por uma amostra equivalente a 18 alunos egressos, $60 \%$ do total de alunos formados pelo referido curso.

Dos respondentes, seis afirmaram ter escolhido cursar Tecnologia em Hotelaria somente para obter um diploma de ensino superior. Uma parcela igual sinalizou ter escolhido o curso porque sempre quis trabalhar na área de turismo/hotelaria. Do restante, apenas três alegaram que os outros cursos oferecidos na região não os interessavam e outros três apresentaram outras justificativas, como o interesse em aprender outras línguas presentes na grade curricular do curso e o fato de trabalhar na Secretaria de Cultura e Turismo da cidade de Limoeiro do Norte.

Embora alguns alunos tenham afirmado possuir interesse em atuar no ramo do turismo e/ou hotelaria, apenas um deles afirmou trabalhar na área, mais especificamente ministrando um curso no segmento de turismo e hotelaria no Serviço Nacional do Comércio (Senac) do estado de Pernambuco. A maior parte, 17 alunos, não encontrou colocação nos meios de hospedagens da própria região, nem de outras localidades.

Quando indagados sobre o motivo pelo qual não estão trabalhando na área de hotelaria do município e de seu entorno, dez afirmaram ter conseguido um emprego em outra área de atuação. Cinco afirmaram que os meios de hospedagens da região não estão dispostos a contratar a mão de obra recém-qualificada. Dois alegaram que não possuem interesse em trabalhar na área, sem especificar o motivo. Outro aluno mencionou a falta de vagas de emprego nos hotéis e similares da região, o que o impulsiona a busca por ocupações de trabalho em outras áreas.

Dos ex-alunos entrevistados, 15 afirmaram nunca ter trabalhado na área e apenas três haviam exercido (ou exerciam no momento da entrevista) alguma atividade relacionada à área. Entre os que conseguiram inserção no mercado turístico/hoteleiro, um já apresentava alguma experiência antes de ingressar no curso de Tecnologia em Hotelaria e somente dois conseguiram ocupações após a conclusão do referido curso.

Quando interrogados acerca do motivo de não estarem mais exercendo atividade na área do turismo/ hotelaria, os alunos alegaram ter conseguido um emprego melhor, tendo em vista que a remuneração financeira e as condições de trabalho oferecidas pelos hotéis e similares da região não são consideradas atrativas. Um dos entrevistados alegou ter se distanciado do setor para ingressar em um curso de pósgraduação.

De todos os alunos que responderam ao questionário, apenas um afirmou ter ido a algum meio de hospedagem em busca de inserção no mercado de trabalho. Para ele, no entanto, o estabelecimento não demonstrou interesse em sua contratação, talvez por não ter condições de pagar um salário compatível 
com a sua formação. Essa é a percepção da maioria dos alunos egressos, mesmo daqueles que ainda não buscaram emprego nos hotéis da região.

É consenso entre os entrevistados que os donos dos meios de hospedagens da região não estão dispostos a remunerar adequadamente os profissionais formados. Alguns acrescentaram que, pelo fato de configurarem-se na categoria de pequeno porte, os hotéis da região não oferecem boas oportunidades de emprego e as condições de trabalho não são satisfatórias. Outros afirmaram que os donos desses estabelecimentos preferem contratar amigos e parentes e que falta o reconhecimento por parte dos empresários do setor de que o aluno egresso da academia está apto a entrar no mercado de trabalho.

Quando questionados sobre a importância do curso para a sua vida profissional, 17 responderam que o curso de Tecnologia em Hotelaria não contribuiu para que eles pudessem ser inseridos no mercado de trabalho na área do turismo/hotelaria da região e 13 afirmaram que o curso também não contribuiu para que pudessem conseguir colocações em outras áreas. Apenas um afirmou que o curso ajudou a obter emprego na área e cinco informaram que o curso ajudou a conseguir emprego em outros setores.

\section{HOTELEIROS DA CIDADE DE LIMOEIRO DO NORTE}

Após uma consulta ao banco de dados do setor de tributação da Prefeitura Municipal de Limoeiro do Norte, verificou-se que cinco meios de hospedagens da cidade possuíam cadastro no órgão. Entretanto, apenas quatro estavam ativos. Um estava inativo e já não existia mais. Todos eles foram visitados para a aplicação do questionário, que foram direcionados às pessoas responsáveis pela contratação dos funcionários. Em geral, verificou-se que esse profissional ou era o próprio empregador, dono do local, ou algum de seus familiares.

Os quatro empreendimentos pesquisados empregam, ao todo, 38 funcionários, ou seja, uma média aproximada de dez funcionários por hotel. Esse número não varia muito ao longo do ano, visto que o público-alvo desses estabelecimentos são representantes comerciais que visitam a cidade e região a trabalho ao longo de todo o ano.

Os empregados desses estabelecimentos ocupam os cargos de recepcionistas, camareiras, lavadeiras, cozinheiros, vigias, auxiliares de manutenção, copeiros, governantas e gerentes.

Vale ressaltar que estes dois últimos cargos, considerados de chefia e, consequentemente, de confiança, são ocupados pelos proprietários do empreendimento ou por algum parente. Os demais cargos, considerados operacionais, são preenchidos mediante a contratação de profissionais que não fazem parte do círculo familiar do proprietário.

O instrumento mais utilizado para se realizar essas contratações é a indicação: todos mencionaram fazer uso dessa ferramenta para selecionar seus funcionários. Além disso, dois afirmaram também receber currículos para análise e apenas um declarou já ter recorrido aos bancos de emprego, sem obter, entretanto, o resultado esperado.

Quando indagados sobre o nível de escolaridade dos funcionários, alguns não tiveram certeza ao responder, porém, afirmaram que a maioria possuía o ensino médio, principalmente os recepcionistas. Já os cozinheiros e camareiras, em geral, possuem apenas o ensino fundamental, muitas vezes incompleto. Foi informado, ainda, que dos 38 funcionários, dois estavam cursando o ensino superior. As áreas escolhidas 
não possuem envolvimento direto com a cadeia produtiva do turismo: um está cursando enfermagem; o outro, contabilidade. Com ensino superior completo foi identificado apenas um funcionário, que possui graduação na área de educação.

Ao serem questionados se a formação acadêmica era um fator levado em consideração na hora da contratação, três afirmaram que esse não era um fator relevante. Utilizando a palavra de um dos entrevistados, resume-se o pensamento da maioria da seguinte forma: "basta que a pessoa tenha disposição para trabalhar". Para eles, este se caracteriza como único requisito para atuar na área.

Dos quatro interrogados, apenas um afirmou exigir escolaridade mínima para contratação de funcionários. Este alegou que para os cargos de camareira e cozinheira, exigia-se, pelo menos, ensino fundamental completo, enquanto que para os cargos de recepcionista, exigia-se comprovação de conclusão do ensino médio.

Por outro lado, metade dos entrevistados afirmou não ser necessária nenhuma formação complementar para se trabalhar na área, enquanto a outra metade afirmou que seria interessante que seus funcionários procurassem aprender uma segunda língua, principalmente o inglês, mas essa formação não se constitui como requisito obrigatório para trabalhar no estabelecimento.

Ao serem indagados acerca do conhecimento sobre a existência do curso de Tecnologia em Hotelaria na cidade, todos afirmaram já ter ouvido falar do referido curso e ter recebido alguns alunos para a realização de capacitação e de visitas técnicas. Porém, quando perguntados se já haviam contratado algum aluno egresso do curso, três responderam negativamente e apenas um respondeu positivamente, nesse caso, o referido aluno se tratava da filha do dono do hotel que ainda estava concluindo o curso.

Quando interrogados sobre o motivo pelo qual não se realizou a contratação de nenhum aluno egresso, dos três que responderam negativamente, um afirmou que nenhum aluno havia procurado emprego no hotel, destacando, ainda, que o curso não oferecia o conhecimento necessário, pois os alunos egressos não possuíam experiência na área. Outro alegou que o curso não se faz necessário diante da realidade local e que o estabelecimento não tem condições de pagar um salário compatível com a formação de um profissional tão qualificado. Por fim, o último afirmou que, por se tratar de um negócio familiar, a formação no curso em questão se torna desnecessária.

Sobre a disponibilidade em receber alunos que ainda estão frequentando o curso de Tecnologia em Hotelaria para a realização de estágios, três dos entrevistados afirmaram que poderia receber esses alunos e apenas um alegou que o hotel não tem interesse na atividade. Em relação à modalidade do estágio, todos ressaltaram que este poderia ser remunerado ou não, e que o valor dessa remuneração poderia ser negociado na hora da contratação, sem mencionar nenhum valor específico.

\section{DISCUSSÃO}

Pode-se concluir, após a finalização deste estudo, que os alunos egressos do curso de Tecnologia em Hotelaria do polo Limoeiro do Norte da Universidade Aberta do Brasil, em sua quase totalidade, não encontraram oportunidade de inserção no mercado de trabalho da hotelaria da região, embora muitos tenham demonstrado interesse em atuar no setor. 
Nota-se também que são poucas as possibilidades de trabalho para o profissional formado na área na cidade, e que as vagas ofertadas nos estabelecimentos são apenas de nível operacional, ficando os cargos de nível tático e estratégico reservados aos donos dos estabelecimentos e/ou seus familiares.

Esse fator pode explicar a falta de interesse, por parte do aluno graduado, em procurar emprego nesses estabelecimentos. A percepção de que estes não estão dispostos a remunerar sua mão de obra de forma adequada, fato comprovado por um dos entrevistados, também pode justificar esse comportamento.

Outra conclusão a que se pode chegar é a de que os donos dos meios de hospedagens da cidade não exigem uma formação técnica ou acadêmica específica na área de hotelaria e/ou turismo. Em alguns estabelecimentos, o responsável pela contratação não exige sequer a comprovação de um grau mínimo de escolaridade.

No entanto, essa realidade não é exclusiva da cidade estudada. Nos estudos utilizados como referencial para este artigo, verifica-se que ela é recorrente no Brasil e também em outros países, como mostra os estudos feitos por Hoerner e Sicart (2013 apud PIMENTEL et al., 2018) e Eurico, Silva e Vale (2012).

Pode-se inferir, com isso, que essa condição é sintomática do distanciamento entre a coordenação do curso e do polo de apoio presencial e os meios de hospedagem locais e da região, que ao longo desses anos não têm firmado parcerias, como foi possível verificar através da aplicação dos questionários.

Contudo, a maioria dos hotéis demonstrou interesse no diálogo ao manifestar a disponibilidade em receber os graduandos para a realização de estágio, item que não consta na grade curricular do curso, nem como disciplina obrigatória nem como eletiva.

Em conformidade com o que diz o projeto pedagógico do curso de Tecnologia em Hotelaria na modalidade a distância, os coordenadores de polo devem celebrar convênios e/ou acordos de colaboração com instituições/empresas locais, em localidades próximas e em Fortaleza para a realização das práticas profissionais.

Compete à coordenação do curso, junto com o coordenador do polo de apoio presencial e os tutores presenciais, criar um ambiente propício para que essa parceria realmente se efetive e seja realizada da maneira adequada, criando oportunidade para a inserção dos alunos egressos do curso no mercado de trabalho local/regional.

A realização dessa atividade pode servir como meio de aproximação entre esses dois agentes, fazendo com que se estabeleça cooperação entre ambos no intuito de mudar essa realidade.

Caso isso não ocorra, cabe aqui um questionamento sobre a viabilidade da continuidade da oferta desse curso no município, uma vez que este não tem atingido seu objetivo, que é o de formar profissionais para assumir funções administrativas e tático-operacionais na área de hospedagem, sala bar e comercial dos meios de hospedagem.

Será que o dinheiro público empregado na manutenção desse curso não estaria sendo melhor empregado na oferta de outro curso ou de outra atividade dessa instituição de ensino? Não seria mais prudente fazer um estudo sobre as reais necessidades do mercado de trabalho local e formar profissionais de áreas que tenham a possibilidade de serem absorvidos em nível local/regional? 


\section{REFERÊNCIAS}

BENI, M. C. Análise estrutural do turismo. 4. ed. São Paulo: Editora Senac, São Paulo, 2001.

BRASIL. Ministério do Turismo. Diretrizes Nacionais para Qualificação em Turismo. Brasília, 2015. Disponível em: 〈http://www.turismo.gov.br/images/pdf/DNQT_Diretrizes_Nacionais_ Qualificacao_03_03_2015.pdf〉. Acesso em: 04 jun. 2018.

BRONCANO, S. G.; ANDRÉS, M. R. El factor humano en los sistemas de gestión de calidad del servicio: un cambio de cultura en las empresas turísticas. Cuadernos de Turismo, Espanha n. 23, p. 129-147, apr. 2009. ISSN: 1139-7861. Disponivel em: 〈www.redalyc.org/articulo.oa?id=39811874007〉. Acesso em: 01 jun. 2018.

CARVALHO, M. A. Educação superior em hotelaria: um exercício de aproximação das diretrizes curriculares brasileiras à realidade do mercado de trabalho em São Paulo. 2003. 180 p. Dissertação (Mestrado em Ciências da Comunicação, Área de Concentração, Turismo e Lazer) - Escola de Comunicação e Artes da Universidade de São Paulo.

CEARÁ. Secretaria de Turismo. Evolução recente do turismo no Ceará 2006/2016. Disponível em: 〈http:// www.setur.ce.gov.br/images/PDFs/ESTUDOS-PESQUISAS/indicadores-turismo-2010-2016-02.pdf`. Acesso em: 31 mai. 2018.

CONCEIÇÃO, R. D. P.; FRAGA, T. F.; CONCEIÇÃO, M. P. Qualificação profissional: um panorama comparativo entre hotéis e pousadas de Petrópolis-RJ. Revista Turismo em Análise, Brasil, v. 27, n. 1, p. 178-206, apr. 2016. ISSN 1984-4867. Disponível em: 〈http://www.revistas.usp.br/rta/article/ view/114849 . Acesso em: 01 jun. 2018.

EURICO, S. T. ; SILVA, J. A. M.; VALLE, P. O. Recursos humanos qualificados no turismo: factores de diferenciação nos polos de desenvolvimento turístico do oeste e de Leiria-Fátima. Encontros Científicos - Tourism \& Management Studies, n. 8, 2012. ISSN-e 2182-8466. Disponível em: 〈https:// dialnet.unirioja.es/servlet/articulo?codigo=4789078>. Acesso em: 01 jun. 2018.

GAIO, C.; FERNANDES, L. R. Perfil do bacharel em turismo: a disparidade entre a realidade da formação profissional e a necessidade do mercado de trabalho. SEMINÁRIO DE PESQUISA EM TURISMO DO MERCOSUL, 7 e 8 de jul. de 2006. Caxias do Sul. 2006.

INSTITUTO FEDERAL DE EDUCAÇÃO, CIÊNCIA E TECNOLOGIA DO CEARÁ. Tecnologia em hotelaria: projeto pedagógico do curso. Fortaleza, 2013.

MELO, A.; GONÇALVES, M. Que competências para a formação superior em gestão hoteleira? A perspectiva de diretores de curso do ensino superior politécnico em Portugal. Tourism and Hospitality International Journal, Portugal, v. 5 n. 1, p. 88-107. set. 2015. ISSN: 2183-0800. Disponível em: 〈http:// hdl.handle.net/10773/17825>. Acesso em: 04 jun. 2018.

MENDES, B. C.; SANTOS, R. S. A empregabilidade no setor de hotelaria: uma análise preliminar. Disponivel em: 〈http://www.anptur.org.br/ocs/index.php/seminario/2009/paper/viewFile/153/14〉. Acesso em: 30 jan. 2014.

MOTA, K. C. N.; SILVA, A. R. Competências para o mercado de trabalho em turismo e hotelaria: perfil dos profissionais requerido em Fortaleza. Conexões: Ciência e Tecnologia. Fortaleza/CE, v. 7, n. 1, p. 9-30, mar. 2013. 
PAIVA, K.; SANTOS, A.; LACERDA, M. Competências gerenciais e sua gestão na hotelaria: um estudo com gestores brasileiros. Tourism \& Management Studies, Faro, v. 10, n. 2, p. 84-93, jul. 2014. Disponível em: 〈http://www.scielo.mec.pt/scielo.php?script=sci_arttext\&pid=S2182-84582014000200011\&ln $\mathrm{g}=\mathrm{pt} \& \mathrm{nrm}=$ iso . Acesso em: 02 jun. 2018.

PEQUENO, E. A. Ensino superior em turismo: uma análise da relação dos cursos acadêmicos de turismo da cidade de Natal-RN e o mercado de trabalho na percepção dos egressos nos anos de 2009 e 2010. 2012. 151 p. Dissertação (Mestrado em Turismo) - Programa de Pós-graduação em Turismo da Universidade Federal do Rio Grande do Norte.

PIMENTEL, T. D. et al. Definição de Competências Laborais em Turismo: implicações sobre o perfil profissional. Revista Latino-Americana de Turismologia, [S.I.], v. 3, n. 2, p. 63-69, maio 2018. ISSN 2448-198X. Disponivel em: 〈https://rlaturismologia.ufjf.emnuvens.com.br/rlaturismologia/article/ view/97>. Acesso em: 02 jun. 2018.

ROBLEDO, J. L. R.; ARÁN, M. V.; PÉREZ-ARANDA, J. Gestión del conocimiento y orientación al marketing interno en el desarrollo de ventajas competitivas en el sector hotelero. Investigaciones Europeas de Dirección y Economía de la Empresa. Espanha, v. 21, n. 2, p. 84-92, mai./ago. 2015. ISSN: 1135-2523. Disponivel em: 〈http://www.elsevier.es/es-revista-investigaciones-europeas-direccion-economiaempresa-345-articulo-gestion-del-conocimiento-orientacion-al-S1135252314000203?redirectNew=true . Acesso em: 01 jun. 2018.

SANTOS, R. A.; SILVA, L. P. Princípios e valores organizacionais: a questão do treinamento e a excelência dos serviços hoteleiros. Um estudo de caso na JW Marriott Rio de Janeiro. Revista Brasileira de Pesquisa em Turismo, São Paulo, v. 9, n. 3, p. 422-441, set./dez. 2015. ISSN: 1982-6125. Disponível em: 〈https://rbtur.org.br/rbtur/article/view/876〉. Acesso em: 01 jun. 2018.

WORLD TRAVEL \& TOURISM COUNCIL. Travel \& Tourism Economic Impact 2018 - Brazil. 2018. Disponível em: $\quad$ https://www.wttc.org/-/media/files/reports/economic-impact-research/countries-2018/ brazil2018.pdf〉. Acesso em: 06 jun. 2018. 